Check for updates

Cite this: Phys. Chem. Chem. Phys., 2018, 20, 7579

Received 24th December 2017, Accepted 19th February 2018

DOI: $10.1039 / c 7 c p 08610 e$

rsc.li/pccp

\section{The kinetics and mechanism of oxidation of reduced phosphovanadomolybdates by molecular oxygen: theory and experiment in concert $\uparrow$}

\author{
Alexander M. Khenkin, Irena Efremenko, Jan M. L. Martin (D) and \\ Ronny Neumann (1D)*
}

\begin{abstract}
The reactivity of the $\mathrm{H}_{5} \mathrm{PV}_{2} \mathrm{MO}_{10} \mathrm{O}_{40}$ polyoxometalate and its analogues as an electron transfer and electron transfer-oxygen transfer oxidant has been extensively studied in the past and has been shown to be useful in many transformations. One of the hallmarks of this oxidant is the possibility of its re-oxidation with molecular oxygen, thus enabling aerobic catalytic cycles. Although the re-oxidation reaction was known, the kinetics and mechanism of this reaction have not been studied in any detail. Experimentally, we show that both the one- and two-electron reduced polyoxometalate are reactive with $\mathrm{O}_{2}$, the two-electron one more so. The reactions are first-order in the polyoxometalate and $\mathrm{O}_{2}$. Solvents also have a considerable effect, protic solvents being preferred over aprotic ones. $\mathrm{H}_{5} \mathrm{PV}_{2} \mathrm{MO}_{10} \mathrm{O}_{40}$ was reduced either by an electron transfer reaction $\left(\mathrm{H}_{2}\right)$ or an electron transfer-oxygen transfer reaction $\left(\mathrm{Ph}_{3} \mathrm{P}\right)$. Similar rate constants and activation parameters were observed for both. DFT calculations carried out on the re-oxidation reactions strongly suggest an inner-sphere process. The process involves first the formation of a coordinatively unsaturated site (CUS) and subsequently the binding of $\mathrm{O}_{2}$ to form superoxo and then peroxo $\eta^{2}-\mathrm{O}_{2}$ adducts. Most interestingly, although vanadium is the reactive redox centre as well as a necessary component for the oxidative activity of $\mathrm{H}_{5} \mathrm{PV}_{2} \mathrm{MO}_{10} \mathrm{O}_{40}$, and a CUS can be formed at both Mo and $\mathrm{V}$ sites, $\mathrm{O}_{2}$ coordination occurs mostly at the Mo CUSs, preferably those where the vanadium centers are distal to each other.
\end{abstract}

\section{Introduction}

Molecular oxygen is a very attractive oxidant for the oxidative transformation of industrially relevant substrates. However, its direct interaction with organic compounds, particularly in the oxidation of hydrocarbons, is characterized by low selectivity because of radical chain reactions associated with the prevalence of oxo and peroxo radical intermediates. One alternative approach for use of dioxygen is its use as a terminal oxidant in oxidase type reactions, such as those catalysed by $\mathrm{Pd}$ compounds, ${ }^{1}$ or those catalysed by phosphovanadomolybdates, notably the $\mathrm{H}_{5} \mathrm{PV}_{2} \mathrm{Mo}_{10} \mathrm{O}_{40}$ of the $\alpha$-Keggin structure. ${ }^{2-9}$ In the latter reactions, substrates are typically activated by electron transfer (ET) to yield either a dehydrogenated product or an oxygenated product by further oxygen transfer (OT). Over the years, reactions involving $\mathrm{C}-\mathrm{H}, \mathrm{C}-\mathrm{C}$ and $\mathrm{C}-\mathrm{M}$ bond activation as

Department of Organic Chemistry, Weizmann Institute of Science, Rehovot, 76100, Israel. E-mail: ronny.neumann@weizmann.ac.il

$\dagger$ JMLM is the Baroness Thatcher Professor of Chemistry. RN is the Rebecca and Israel Sieff Professor of Organic Chemistry.

\$ Electronic supplementary information (ESI) available: Additional experimental kinetic data and computational data. See DOI: 10.1039/c7cp08610e well as oxidation of sulphides have been studied. ${ }^{7-9}$ Importantly, the reduced catalyst, whose structure has been studied by EPR experiments $^{10,11}$ and DFT calculations, ${ }^{12}$ can be re-oxidized by molecular oxygen. This spatiotemporal separation between the substrate oxidation and the catalyst regeneration is responsible for high selectivity of such reactions. It should be stressed, as indicated in Scheme 1, that the reaction of one equivalent of $\mathrm{H}_{5} \mathrm{PV}_{2} \mathrm{Mo}_{10} \mathrm{O}_{40}$ with one equivalent of substrate or reducing agent typically leads first to an observable intermediate consisting of an oxidized substrate and reduced $\mathrm{H}_{5} \mathrm{PV}_{2} \mathrm{Mo}_{10} \mathrm{O}_{40} \cdot{ }^{7-12}$ In principle, in the presence of $\mathrm{O}_{2}$ two scenarios can be considered for a catalytic reaction that includes re-oxidation of the reduced $\mathrm{H}_{5} \mathrm{PV}_{2} \mathrm{Mo}_{10} \mathrm{O}_{40}$ : (i) product formation as shown in Scheme 1 followed by catalyst re-oxidation; and (ii) direct aerobic oxidation of the intermediate as recently demonstrated in the oxidation of benzene. ${ }^{13}$

$$
\begin{aligned}
& \text { Dehydrogenation }
\end{aligned}
$$

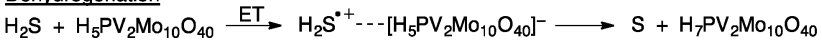

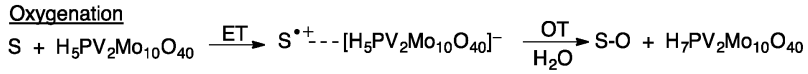

Scheme 1 Oxidation of generic substrates (S) by $\mathrm{H}_{5} \mathrm{PV}_{2} \mathrm{MO}_{10} \mathrm{O}_{40}$. 
Thus, although much is known about the mechanisms of substrate oxidation, much less is known about the reactions of reduced polyoxometalates with oxygen. It has thus been shown that a $\mathrm{Fe}(\mathrm{II})$-substituted polyoxotungstate binds $\mathrm{O}_{2},{ }^{14}$ but more generally the re-oxidation of reduced polyoxotungstates with $\mathrm{O}_{2}$ in water has been shown to proceed by an outer-sphere electron transfer (ET). ${ }^{15-17}$ The mechanism is less clear in the case of phosphovanadomolybdates. Moreover, although the redox potentials for different $\alpha$-Keggin polyoxometalates show the following general trend, polyoxotungstates $<$ polyoxomolybdates $<$ polyoxovanadomolybdates, ${ }^{18}$ the rates of their aerobic re-oxidation are not correlated with the redox potential: polyoxotungstates (seconds) 》 polyoxovanadomolybdates (minutes) 》 polyoxomolybdates (days). It was suggested that aerobic re-oxidation of $\mathrm{H}_{6} \mathrm{PV}^{\mathrm{V}} \mathrm{V}^{\mathrm{IV}} \mathrm{Mo}_{10} \mathrm{O}_{40}$ after reaction with $\alpha$-terpinene occurs through inner-sphere electron transfer to oxygen, ${ }^{19}$ but other publications suggest different scenarios. ${ }^{20-22}$ Herein, we examine the mechanism of oxidation of reduced $\mathrm{H}_{5} \mathrm{PV}_{2} \mathrm{Mo}_{10} \mathrm{O}_{40}$ by $\mathrm{O}_{2}$ under conditions similar to practical catalytic oxidation applications. In order to understand the mechanism at the atomic and electronic level, the experimental studies were combined with density functional theory (DFT) calculations. It is known that important factors for $\mathrm{O}_{2}$ activation include, but are not limited to, redox potential, solvent, spin state, ligand architecture, and additional co-reductants. ${ }^{23,24}$ In this work we have considered the oxidation of $\mathrm{H}_{6} \mathrm{PV}_{2} \mathrm{Mo}_{10} \mathrm{O}_{40}$ and $\mathrm{H}_{7} \mathrm{PV}_{2} \mathrm{Mo}_{10} \mathrm{O}_{40}$ by molecular oxygen.

\section{Results and discussion}

\section{Kinetics of aerobic oxidation}

As can be seen from Scheme 1 the reaction of $\mathrm{H}_{5} \mathrm{PV}_{2} \mathrm{Mo}_{10} \mathrm{O}_{40}$ (the oxidized compound, $\mathbf{1}_{\mathbf{o x}}$ ) with substrates either by an ET dehydrogenation or an ET-OT oxygenation is intrinsically a two-electron process. However, self-exchange ET between polyoxometalates is fast, ${ }^{2,15,17}$ that is, the two-electron reduced $\mathrm{H}_{7} \mathrm{PV}_{2} \mathrm{Mo}_{10} \mathrm{O}_{40}\left(\mathbf{1}_{\text {red2e }}\right)$ can readily react with $\mathbf{1}_{\mathbf{o x}}$ to yield the one-electron reduced $\mathrm{H}_{6} \mathrm{PV}_{2} \mathrm{Mo}_{10} \mathrm{O}_{40}\left(\mathbf{1}_{\text {red1e }}\right)$. According to our calculations, this interaction is exergonic by $3.73 \mathrm{kcal} \mathrm{mol}^{-1}$ in acetonitrile and is favoured kinetically by the strong acidic nature of the surface protons. Therefore, the substrate $/ \mathbf{1}_{\mathbf{o x}}$ ratio can be manipulated to form either $\mathbf{1}_{\text {red1e }}$ or $\mathbf{1}_{\text {red2e }}$. Molecular hydrogen, $\mathrm{H}_{2}$, is the simplest reducing agent, since there is no product formed besides $\mathbf{1}_{\text {red1e }}$ or $\mathbf{1}_{\text {red2e }}$. Thus, $\mathbf{1}_{\text {red1e }}$ and $\mathbf{1}_{\text {red2e }}$ can be formed by the reaction of 0.5 equivalents and 1.0 equivalent of $\mathrm{H}_{2}$ with $\mathbf{1}_{\mathrm{ox}}$, respectively, as in eqn (1):

$$
\mathrm{H}_{2}+\mathbf{1}_{\mathrm{ox}} \rightarrow \mathbf{1}_{\text {red2e }} \text { and } \mathbf{1}_{\text {red2e }}+\mathbf{1}_{\mathrm{ox}} \rightarrow \mathbf{1}_{\text {red1e }}
$$

In the reaction of either the one- or two-electron reduced species ( $\mathbf{1}_{\text {red }}$ ) with $\mathrm{O}_{2}$ in $\mathrm{CH}_{3} \mathrm{CN}, 1$ equivalent of $\mathrm{O}_{2}$ was consumed per 2 equivalents and 4 equivalents, respectively, of $\mathbf{1}_{\text {red2e }}$ and $\mathbf{1}_{\text {red1e }}$, as determined by volumetric measurements, Table S1 (ESI $\$$ ). Therefore, we conclude that $\mathbf{1}_{\text {redze }}$ and $\mathbf{1}_{\text {red1e }}$ react with $\mathrm{O}_{2}$ according to eqn (2) and (3), respectively:

$$
\begin{aligned}
& 2 \mathrm{H}_{7} \mathrm{PV}_{2} \mathrm{Mo}_{10} \mathrm{O}_{40}+\mathrm{O}_{2} \rightarrow 2 \mathrm{H}_{5} \mathrm{PV}_{2} \mathrm{Mo}_{10} \mathrm{O}_{40}+2 \mathrm{H}_{2} \mathrm{O} \\
& 4 \mathrm{H}_{6} \mathrm{PV}_{2} \mathrm{Mo}_{10} \mathrm{O}_{40}+\mathrm{O}_{2} \rightarrow 4 \mathrm{H}_{5} \mathrm{PV}_{2} \mathrm{Mo}_{10} \mathrm{O}_{40}+2 \mathrm{H}_{2} \mathrm{O}
\end{aligned}
$$

The kinetics of reoxidation of $\mathbf{1}_{\text {red }}$ in acetonitrile was studied spectrophotometrically, by following the disappearance of the reduced polyoxometalate blue colour at $750 \mathrm{~nm}$. Typical kinetic curves are shown in Fig. S1 (ESI $\ddagger$ ). The reaction order with respect to the concentration $\left[\mathbf{1}_{\text {red }}\right]$ was determined by measuring the initial rate, $-\mathrm{d}\left[\mathbf{1}_{\text {red }}\right] / \mathrm{d} t$, as a function of the initial concentration of $\left[\mathbf{1}_{\text {red }}\right],\left[\mathbf{1}_{\text {red }}\right]_{0}$, at a constant initial concentration of $\left[\mathrm{O}_{2}\right]$. The linear increase in the initial rate with the increase in $\mathbf{1}_{\text {red }}$ over a wide range of $\left[\mathbf{1}_{\text {red }}\right]_{0}$ reveals the reaction to be first-order with respect to $\left[\mathbf{1}_{\text {red }}\right]$ reduced by either 1 or 2 electrons, Fig. S2 (ESI $\ddagger$ ). Similarly, the linear dependence of the initial rate on $\left[\mathrm{O}_{2}\right]_{0}$, Fig. $\mathrm{S} 3$ (ESI $\%$ ), indicates that the reaction is first order with respect to $\mathrm{O}_{2}$. Therefore, the direct reaction of $\mathbf{1}_{\text {red }}$ with $\mathrm{O}_{2}$ obeys the rate law as shown in eqn (4):

$$
\mathrm{d}\left[\mathbf{1}_{\text {red }}\right] / \mathrm{d} t=k\left[\mathbf{1}_{\text {red }}\right]_{0}\left[\mathrm{O}_{2}\right]_{0}
$$

From this equation, one can calculate a rate constant for $\mathbf{1}_{\text {red1e }}$, $k_{298}=0.09 \pm 0.02 \mathrm{M}^{-1} \mathrm{~s}^{-1}$. This rate constant is two orders of magnitude lower than that for oxidation of one electron reduced polyoxotungstates in water. ${ }^{15}$ The rate constant for the reoxidation of $1_{\text {red2e }}$ is $k_{298}=0.9 \pm 0.1 \mathrm{M}^{-1} \mathrm{~s}^{-1}$, which is an order of magnitude higher than that measured for $\mathbf{1}_{\text {redie }}$. In addition, once the blue colour associated with $\mathbf{1}_{\text {red }}$ disappeared, iodometric titration revealed that no $\mathrm{H}_{2} \mathrm{O}_{2}$ was present in the reaction mixture, although this does not rule out the possibility of $\mathrm{H}_{2} \mathrm{O}_{2}$ as a fast-reacting oxidizing intermediate. Indeed, a control experiment on the oxidation of $\mathbf{1}_{\text {redie }}$ by $\mathrm{H}_{2} \mathrm{O}_{2}$ yielded a rate constant, $k_{298}=3.2 \pm 0.8 \mathrm{M}^{-1} \mathrm{~s}^{-1}$, which is significantly higher than the one with $\mathrm{O}_{2}$ as oxidant.

It is worth noting that the initial rates, $V_{0}$, for the aerobic oxidation of $\mathbf{1}_{\text {red }}$ are solvent dependent - although as seen in Table $1, V_{0}\left(\mathbf{1}_{\text {red2e }}\right)$ is always greater than $V_{0}\left(\mathbf{1}_{\text {red1e }}\right)$. Generally, the reactions are faster in protic solvents compared to aprotic ones, although addition of trifluoroacetic acid positively affects the rates in aprotic solvents, while the effect is small for protic solvents. The rate constants are not correlated with the redox potential of 1 in the various solvents.

In addition to the reduction of $\mathbf{1}_{\mathbf{o x}}$ by $\mathrm{H}_{2}$, the reduced polyoxometalate was also formed by a typical but simple ET-OT reaction, that is, the oxidation of triphenylphosphine to the

Table 1 Initial rates for oxidation of $\mathbf{1}_{\text {red }}$ reduced by $\mathrm{H}_{2}$ in different solvents

\begin{tabular}{lccc}
\hline Solvent & $V_{0}\left(\mathbf{1}_{\text {red2e }}\right) \mathrm{M} \mathrm{s}^{-1} \times 10^{7}$ & $V_{0}\left(\mathbf{1}_{\text {red1e }}\right) \mathrm{M} \mathrm{s}^{-1} \times 10^{7}$ & $E(\mathrm{~V})$ \\
\hline Water & $8.4 \pm 0.9$ & $3.70 \pm 0.4$ & 0.50 \\
$0.1 \mathrm{M} \mathrm{H}{ }_{2} \mathrm{SO}_{4}$ & $21.8 \pm 2.5$ & $4.48 \pm 0.4$ & 0.52 \\
AcOH & $15.7 \pm 1.5$ & $4.21 \pm 0.4$ & 0.38 \\
MeOH & $15.1 \pm 1.6$ & $2.92 \pm 0.3$ & nd \\
Acetonitrile & $3.6 \pm 0.5$ & $0.36 \pm 0.06$ & 0.49 \\
Sulfolane & $0.6 \pm 0.1$ & $0.12 \pm 0.02$ & 0.50 \\
DMSO & $2.8 \pm 0.3$ & $0.12 \pm 0.02$ & 0.40 \\
Diglyme & $3.1 \pm 0.4$ & $0.24 \pm 0.03$ & 0.45
\end{tabular}

Conditions: $0.25 \mathrm{mM} 1_{\text {red }}, 1$ bar air, $25{ }^{\circ} \mathrm{C}$. The redox potentials were obtained by cyclic voltammetry (see the Experimental section) and standardized versus $\mathrm{Fc} / \mathrm{Fc}^{+}$. Since the solubility of $\mathrm{O}_{2}$ depends somewhat on the solvent, the dependence of the rate of reoxidation of $\mathbf{1}_{\text {red }}$ is presented in terms of initial rates $V_{0}$ rather than rate constants. nd - not determined. 


$$
\begin{aligned}
& \mathrm{Ph}_{3} \mathrm{P}+\mathrm{H}_{5} \mathrm{PVV}_{2} \mathrm{Mo}_{10} \mathrm{O}_{40} \stackrel{25^{\circ} \mathrm{C}}{\longrightarrow} \mathrm{Ph}_{3} \mathrm{P}^{\bullet+}---\mathrm{H}_{5} \mathrm{PVIV}^{\mathrm{IV} V M o}{ }_{10} \mathrm{O}_{40} \\
& \mathrm{Ph}_{3} \mathrm{P}^{\bullet+--} \mathrm{H}_{5} \mathrm{PV}^{I V} \mathrm{~V}^{\mathrm{VMo}}{ }_{10} \mathrm{O}_{40}+\mathrm{H}_{2} \mathrm{O} \stackrel{70}{ } \stackrel{{ }^{\circ} \mathrm{C}}{\longrightarrow} \mathrm{Ph}_{3} \mathrm{P}=\mathrm{O}+\mathrm{H}_{7} \mathrm{PV}_{2}{ }_{2} \mathrm{Mo}_{10} \mathrm{O}_{40}
\end{aligned}
$$

Scheme 2 The ET-OT oxygenation of triphenylphosphine.

Table 2 Rate constants and activation parameters for the aerobic oxidation of $\boldsymbol{1}_{\text {red }}$ formed by different reducing agents (RA)

\begin{tabular}{lcclll}
\hline $\mathrm{RA}$ & $\mathbf{1}_{\text {red }}$ & $k_{298}, \mathrm{M}^{-1} \mathrm{~s}^{-1}$ & $\begin{array}{l}\Delta H_{298}^{\#}, \\
\mathrm{kcal} \mathrm{mol}^{-1}\end{array}$ & $\begin{array}{l}\Delta S_{298}^{\#}, \\
\mathrm{cal} \mathrm{mol}^{-1} \mathrm{~K}^{-1}\end{array}$ & $\begin{array}{l}\Delta G_{298}^{\#}, \\
\mathrm{kcal} \mathrm{mol}^{-1}\end{array}$ \\
\hline $\mathrm{H}_{2}$ & $\mathbf{1}_{\text {red1e }}$ & $0.09 \pm 0.02$ & 8.4 & -32.6 & 18.3 \\
$\mathrm{H}_{2}$ & $\mathbf{1}_{\text {red2e }}$ & $0.9 \pm 0.1$ & 5.4 & -39.8 & 17.3 \\
$\mathrm{Ph}_{3} \mathrm{P}$ & $\mathbf{1}_{\text {red1e }}$ & $0.05 \pm 0.01$ & 8.3 & -36.6 & 19.2 \\
$\mathrm{Ph}_{3} \mathrm{P}$ & $\mathbf{1}_{\text {red2e }}$ & $0.7 \pm 0.1$ & 6.5 & -36.5 & 17.4
\end{tabular}

Conditions: $0.50 \mathrm{mM} \mathbf{1}_{\text {red }}$ in $\mathrm{CH}_{3} \mathrm{CN}, 1$ bar air. Data from Fig. S5 and S6 (ESI).

corresponding oxide, Scheme 2 . At $25{ }^{\circ} \mathrm{C}$, the ion pair formed as a result of electron transfer can be observed by EPR, Fig. S4 (ESI $\ddagger$ ). A ${ }^{31} \mathrm{P}$ NMR measurement at this point shows no formation of triphenylphosphine oxide, which however can easily be formed by heating the mixture to $70{ }^{\circ} \mathrm{C}$.

The rate constants as well as the transition state energies found for the oxidation of $\mathbf{1}_{\text {red }}$ formed by reduction with either $\mathrm{H}_{2}$ or $\mathrm{Ph}_{3} \mathrm{P}$ are presented in Table 2. As one can see, there is some small variation in the values obtained, but they are very similar and likely within experimental uncertainty. Notable is the large negative value of $\Delta S^{\#}$, pointing towards an organized rate-limiting state.

\section{Computational results}

The overall reactions of oxygen reduction by $\mathrm{H}_{7} \mathrm{PV}_{2} \mathrm{Mo}_{10} \mathrm{O}_{40}$ and $\mathrm{H}_{6} \mathrm{PV}_{2} \mathrm{Mo}_{10} \mathrm{O}_{40}$ according to eqn (2) and (3) are energetically highly favourable: $\Delta G_{298}=-57.2$ and $-50.3 \mathrm{kcal} \mathrm{mol}^{-1}$ in acetonitrile, respectively. However, the first step of the interaction, that is the abstraction of the first $\mathrm{H}$-atom or coupled proton-electron transfer (CPET), is endergonic by $13.5 \mathrm{kcal}$ $\mathrm{mol}^{-1}$ for $\mathbf{1}_{\text {red2e }}$ and $16.9 \mathrm{kcal} \mathrm{mol}{ }^{-1}$ for $\mathbf{1}_{\text {red1e. This in }}$ agreement with the strongly negative one-electron reduction potential of oxygen (which is $-0.33 \mathrm{~V} v s$. NHE in water at $\mathrm{pH} 7$, $\left.25{ }^{\circ} \mathrm{C}\right) .{ }^{25}$ The interaction between an acidic surface hydrogen of $\mathbf{1}_{\text {red1e }}$ and apolar $\mathrm{O}_{2}$ leads to a highly unstable intramolecular complex before hydrogen transfer that is $22.4 \mathrm{kcal} \mathrm{mol}^{-1}$ above the energy of the reactants. The subsequent activation barrier for $\mathrm{H}$ transfer is $29.8 \mathrm{kcal} \mathrm{mol}^{-1}$, prohibitively high for a room temperature reaction. See Fig. S7 (ESI $\$$ ) for optimized structures for outer sphere complexes. We were unable to locate a similar precursor complex and transition state for $\mathbf{1}_{\text {redze }}$ using our computational approximation. In both cases the probability of the outer-sphere H-transfer is expected to be extremely low since CPET or $\mathrm{H}$-atom transfers are viewed as vibrational processes that require at least weak hydrogen bonding between the reaction centres. ${ }^{26-28}$

Due to the absence of spin restrictions, electron transfer (ET) is often considered the most probable initial stage of oxygen activation. ${ }^{29,30}$ Our calculations showed that in spite of the high
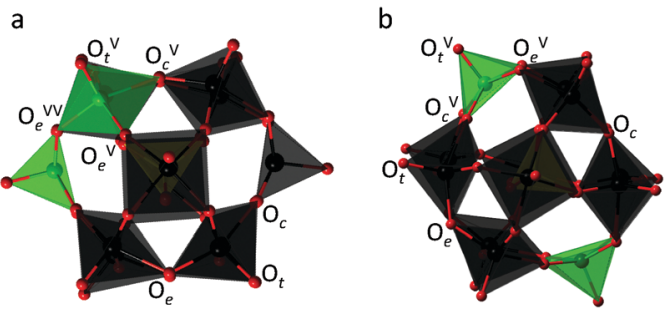

Fig. 1 Surface oxygen atoms in the 1,2 (a) and 1,11 (b) isomers of the $\left[\mathrm{PV}_{2} \mathrm{Mo}_{10} \mathrm{O}_{40}\right]^{q-}$ anion

oxidation potential of oxygen and the presence of lone pair electrons, ET and PT from the reduced polyoxometalates are unacceptably high in energy, especially in the gas phase, Table S2 (ESI ). These results, together with the experimental observations that (a) a catalytic amount of $\mathrm{Cu}^{+}$does not influence the rate of the oxidation reaction and (b) $\mathrm{H}_{2} \mathrm{O}_{2}$ was not observed as an intermediate in the reaction mixture, prompted us to consider an inner-sphere mechanism for aerobic oxidation of $\mathbf{1}_{\text {red. }}$. By way of example, we consider the $(1,2)$ and $(1,11)$ isomers of the $\left[\mathrm{PV}_{2} \mathrm{Mo}_{10} \mathrm{O}_{40}\right]^{q-}$ anion (Fig. 1), which have two vanadium atoms at the proximal and distal positions, respectively, to each other. These isomers were chosen because they represent two different structure types with different reactivity that have been previously observed. ${ }^{10-12}$ According to our calculations, the $(1,2)$ isomers of $\mathbf{1}_{\text {ox }}$ and $\mathbf{1}_{\text {red1e }}$ are 1.5 and $2.2 \mathrm{kcal} \mathrm{mol}^{-1}$ more stable, respectively, than the $(1,11)$ isomer. In contrast, the $(1,11)$ isomer of $\mathbf{1}_{\text {red2e }}$ is $0.6 \mathrm{kcal} \mathrm{mol}^{-1}$ more stable than the corresponding $(1,2)$ isomer.

All 12 metal atoms in the Keggin structure are hexacoordinated with oxo ligands and thus are not likely to coordinate $\mathrm{O}_{2}$. However, we have previously shown that the tendency of vanadium atoms in high oxidation states towards a reduced coordination number facilitates the formation of defect structures with coordinatively unsaturated sites (CUSs). Depending on which bonds are broken, V or Mo CUSs could be formed. ${ }^{12}$ Further calculations reported here show that reduction of the polyoxometalate tends to slightly decrease the energetic cost for such defect formation, while protonation slightly increases it, Table 3. The experimentally observed accelerating effect of protic solvents presents an additional indirect proof for CUS formation as an important stage of interaction.

The bonding analysis, Fig. S9 (ESI $\$$ ), shows that one of the $\mathrm{V}-\mathrm{O}-\mathrm{V}$ bonds represents the weakest bridging bond in the $\mathbf{1}_{\mathbf{o x}}$ $(1,2)$ isomer. Breaking of this bond together with one of the

Table 3 Stability of $V$ and Mo CUSs ( $\Delta G_{298}$ in acetonitrile, $\mathrm{kcal} \mathrm{mol}^{-1}$ ) compared to the corresponding intact structures

\begin{tabular}{llll}
\hline & $(1,2) \mathrm{V}$ CUS & $(1,2) \mathrm{Mo}$ CUS & $(1,11) \mathrm{Mo}$ CUS \\
\hline $\mathrm{H}_{5} \mathrm{PV}_{2} \mathrm{Mo}_{10} \mathrm{O}_{40}$ & 20.54 & 16.50 & 16.25 \\
{$\left[\mathrm{H}_{5} \mathrm{PV}_{2} \mathrm{Mo}_{10} \mathrm{O}_{40}\right]^{-}$} & 19.58 & 17.85 & 14.10 \\
$\mathrm{H}_{6} \mathrm{PV}_{2} \mathrm{Mo}_{10} \mathrm{O}_{40}$ & 22.28 & 16.93 & 14.35 \\
{$\left[\mathrm{H}_{6} \mathrm{PV}_{2} \mathrm{Mo}_{10} \mathrm{O}_{40}\right]^{-}$} & $17.64(19.69)$ & $13.75(17.94)$ & $15.08(16.71)$ \\
$\mathrm{H}_{7} \mathrm{PV}_{2} \mathrm{Mo}_{10} \mathrm{O}_{40}$ & $18.64(19.96)$ & $15.32(18.86)$ & $15.54(21.03)$
\end{tabular}

The energies of 2e-reduced structures in the triplet state are shown in parentheses. The optimized structures of the V and Mo CUS are shown in Fig. S8 (ESI). 
adjacent weak Mo-O or $\mathrm{V}-\mathrm{O}$ bonds leads to molybdenum- or vanadium-centred CUSs, respectively. The electron spin density in intact $\mathbf{1}_{\text {red }}$ is distributed between $t_{1 u}$ orbitals that are nonbonding with respect to $\mathrm{V}-\mathrm{O}$ and $\mathrm{t}_{2 \mathrm{~g}}$ orbitals that are strongly antibonding with respect to Mo-O, Fig. S10 (ESI ). Therefore, the reduction of phosphovanadomolybdates most strongly destabilizes Mo-O bonds, making the formation of molybdenum centred CUSs more preferential. Thus, for the $(1,2)$ isomer of $\mathbf{1}_{\text {red }}$, the formation of a Mo CUS is preferred by $2-5 \mathrm{kcal} \mathrm{mol}^{-1}$ relative to its V counterpart. Moreover, Mo CUSs are usually slightly less endergonic for the $(1,11)$ isomer, especially for $\mathbf{1}_{\text {red1e }}$. In contrast to the intact $\mathbf{1}_{\text {red2e }}$ structures that have triplet ground states, closed-shell electronic configurations are $1.3-5.5 \mathrm{kcal} \mathrm{mol}^{-1}$ more stable for the defect structures. Finally, it is also notable that the presence of water as a coordinated ligand stabilizes defect structures, especially for the $\mathbf{1}_{\mathbf{o x}}$ and $\mathbf{1}_{\text {red1e }}$ with V CUSs, Table S3 and Fig. S11 (ESI $\ddagger$ ).

Now given that the calculations have shown that the CUSs of $\mathbf{1}$ are viable species, they can be also considered as excellent candidates for the ligation of $\mathrm{O}_{2}$ and its activation by an inner sphere reaction. Side-on $\eta^{2}-\mathrm{O}_{2}$, end-on $\eta^{1}-\mathrm{O}_{2}$ and $\eta^{2}-\mathrm{O}_{2} \mathrm{H}$ as well as bridged $\mathrm{M}-\mathrm{O}-\mathrm{O}-\mathrm{M}$ coordination modes of $\mathrm{O}_{2}$ at molybdenum and vanadium sites are shown in Chart 1 , together with their calculated stabilities. Selected bond lengths, vibrational frequencies and atomic charges of these complexes are assembled in Table S4 (ESI $\ddagger$ ). The most notable observation is that the side-on $\eta^{2}-\mathrm{O}_{2}$ coordination to either $\mathrm{Mo}$ or $\mathrm{V}$ in defect structures was found to be the most energetically favourable for the one-electron reduced polyoxometalate. This also holds true for the two-electron reduced polyoxometalate, although here also certain $\mathrm{M}-\mathrm{O}-\mathrm{O}-\mathrm{H}$ species were stable, albeit still less than the side-on $\eta^{2}-\mathrm{O}_{2}$ species. In all considered $(1,2)$ isomers, oxygen binding and activation is preferred at a molybdenum CUS where longer $\mathrm{O}-\mathrm{O}$ bonds, lower $\mathrm{O}-\mathrm{O}$ vibrational frequencies, and greater transfer of electron density were found (Table S4, ESI $\$$ ) compared to the vanadium CUS. The only exception is the end-on coordination mode, for which V superoxo complexes are slightly more stable than the corresponding Mo complexes. The $(1,11)$ isomer possesses only Mo sites that show oxygen binding affinity qualitatively similar to that of the $(1,2)$ isomer.

These findings can be explained by $\pi$-repulsion caused by metal interactions with $\sigma$ - and $\pi$-donating oxygen ligands, and this effect is stronger for $\mathrm{V}$ than for Mo because of the difference in atomic sizes. ${ }^{12}$ For superoxo complexes, the electron transfer from $\mathbf{1}_{\text {red }}$ to $\mathrm{O}_{2}$ is comparable for side-on and end-on coordination modes, resulting in quite similar stabilities of these complexes. In contrast, effective 2e-backdonation from metal to $\mathrm{O}_{2}$ in side-on peroxo complexes results in their dramatically higher stability. Indeed, for $\mathrm{a} \mathrm{V}^{3+}$ complex with bulky amine ligands that does not suffer from $\pi$-repulsion, the side-end peroxo complex was found to be much stronger than in our case $\left(\Delta H=-75.0 \pm 2.0 \mathrm{kcal} \mathrm{mol}^{-1}\right)$ with a much smaller energy difference between the two isomers (4.2 kcal mol ${ }^{-1}$ ), favouring $\eta^{2}$ binding. ${ }^{31}$

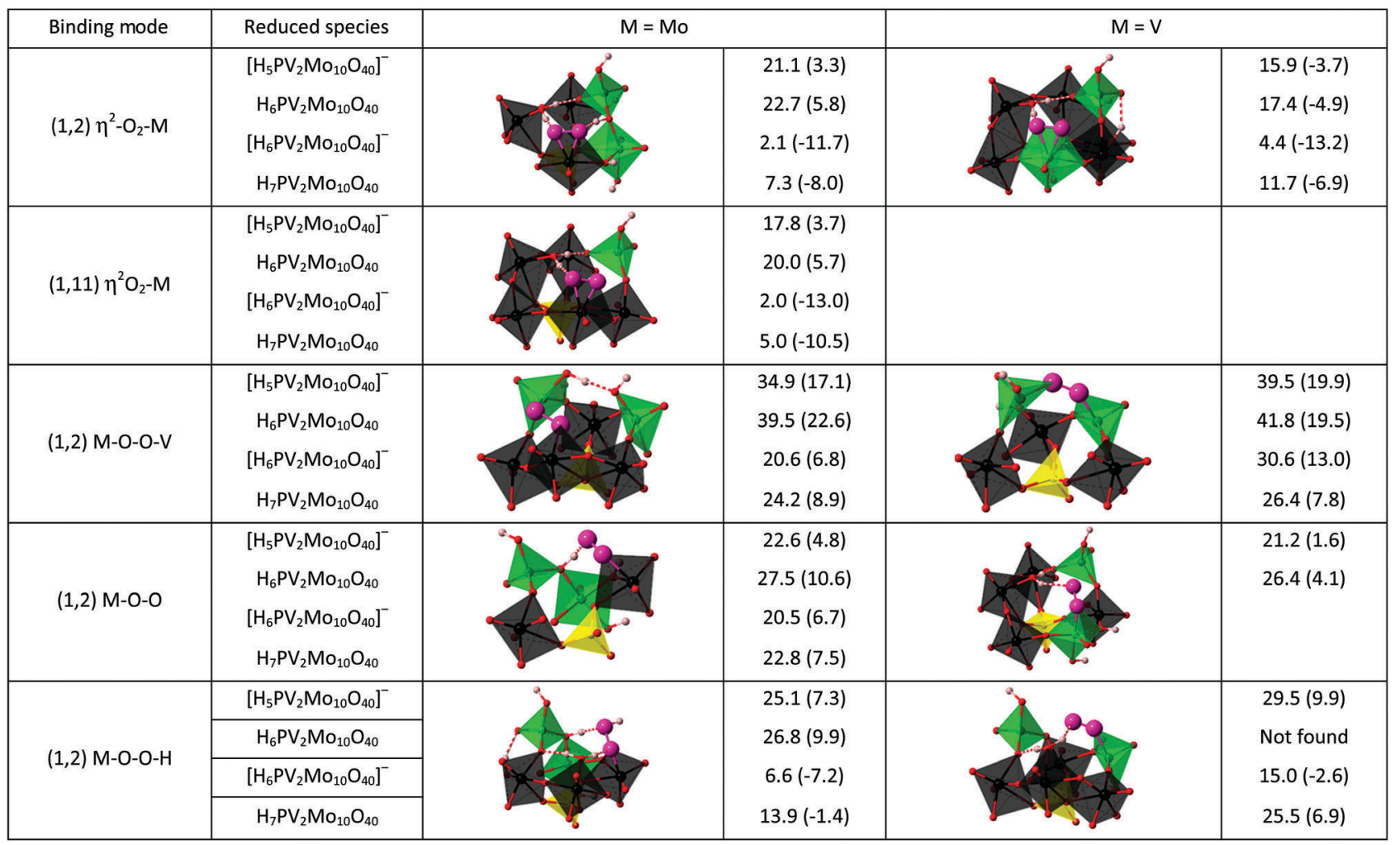

Chart 1 Typical $\mathrm{O}_{2}$ modes of ligation to reduced species of 1 and their calculated stabilities. The free energy, $\Delta G_{298}, \mathrm{kcal} \mathrm{mol}^{-1}$, of the species is given relative to the intact polyoxometalate and to the relevant defect structures (in parentheses). All the complexes are in the lowest possible spin state, that is singlet or doublet. These are the lowest-energy states that were found at the level of theory employed. 
Having the defect structures with CUSs and their oxygen complexes in side-on and end-on binding modes as possible intermediates, the mechanism of inner-sphere oxidation $\mathbf{1}_{\text {red }}$ can be studied in more detail. The first reaction considered was the stoichiometric oxidation of four $\mathrm{H}_{6} \mathrm{PV}_{2} \mathrm{Mo}_{10} \mathrm{O}_{40}, \mathbf{1}_{\text {red1e }}$, species by $\mathrm{O}_{2}$ on three different coordinatively unsaturated sites - Mo CUS in $(1,11)$ and Mo and V CUS in $(1,2)$ isomers, Fig. 2.

Inspection of the reaction profiles in Fig. 2 shows that defect formation and oxygen coordination are the highest energy states in acetonitrile at room temperature. For activation at vanadium, the enthalpy-controlled reaction of V CUS formation would appear to be the rate determining state of the reaction. In contrast, for the Mo CUS, entropy-controlled oxygen coordination represents the limiting state. Energetically, reactions on both Mo and V CUSs have lower barriers than that for the outer-sphere CPET (vide supra).

Transformation of superoxo to peroxo complexes by hydrogen transfer from another $\mathbf{1}_{\text {red1e }}$ species significantly stabilizes oxygen coordination on the Mo CUS. Protonation of coordinated oxygen and subsequent water dissociation are endergonic at this stage by 5-10 kcal mol ${ }^{-1}$. Hydrogen transfer from the third $\mathbf{1}_{\text {red1e }}$ species causes transformation from the side-on to the end-on $\mathrm{M}-\mathrm{OOH}$ coordination mode, in which intramolecular proton transfer and consequent water dissociation take place. These intermediate reactions proceed with small changes in energy, and most of the complexes remain endergonic with respect to the reactants. Transfer of the fourth $\mathrm{H}$-atom completes $4 \mathrm{e}_{2}$ reduction and proceeds with strong energy gain. These energetic trends qualitatively resemble the outer-sphere oxygen reduction (Table S2, ESI $\$$ ).
The last strongly exergonic stage is water dissociation and recovery of $\mathbf{1}_{\mathbf{o x}}$.

Although all points in Fig. 2 correspond to local minima on the corresponding potential energy surface, we believe that the activation barriers are well approximated by the calculated energies of the intermediate structures. The first reaction, formation of defect structures with CUSs, is the only individual step for which a substantial activation barrier could be anticipated. For the most unstable V CUS in the $\mathbf{1}_{\mathbf{o x}}$ isomer, we found a late transition state that was only $3.12 \mathrm{kcal} \mathrm{mol}^{-1}$ higher in energy than the final defect structure. In spite of numerous efforts, we were unable to locate a saddle point on the way to other defect structures, presumably because of close geometric and energetic proximity of the local minima corresponding to the final state. Moreover, the presence of water further stabilizes the transition state. The second reaction is the formation of the $\eta^{2}-\mathrm{O}_{2}-\mathrm{M}$ adducts in the absence of spin restriction for the interaction of $\mathbf{1}_{\text {red1e }}$ with oxygen in its ground state. Finally, self-exchange hydrogen transfer from other $\mathbf{1}_{\text {red1e }}$ species at the next stages of the interaction is fast and is favoured kinetically by the strong acidic nature of the surface protons, vide supra. Reorganization of the $\eta^{2}-\mathrm{O}_{2}$ coordination mode to $\eta^{1}-\mathrm{OOH}$ and the following water dissociation smoothly proceed on the energetic scale and are facilitated by hydrogen bonding (see the corresponding structures in Chart 2). Thus, we believe that the reaction profiles in Fig. 2 represent not only the thermodynamics, but also the kinetics of the $\mathbf{1}_{\text {red1e }}$ oxidation reaction.

Reoxidation of $\mathbf{1}_{\text {red2e }}$ shows specific features, related mainly to the spin state of the systems. As mentioned above, the defect

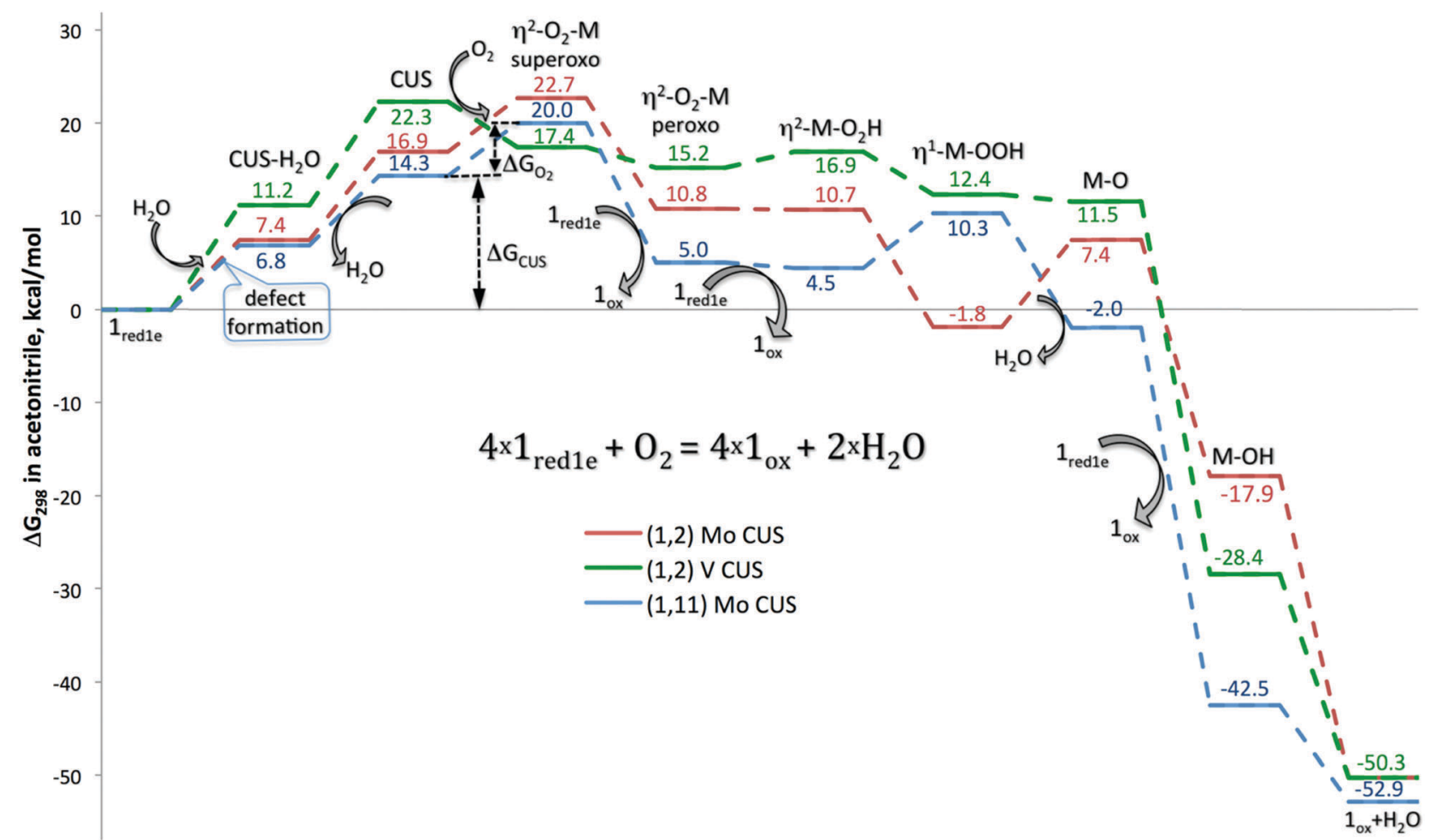

Fig. 2 Reaction profiles for the oxidation of $\mathrm{H}_{6} \mathrm{PV}_{2} \mathrm{Mo}_{10} \mathrm{O}_{40}, \mathbf{1}_{\text {red1e. }}$. All points are local minima on the corresponding potential energy surfaces. 


\begin{tabular}{|c|c|c|c|c|}
\hline & Spin & $\begin{array}{c}\Delta G_{298} \\
\mathrm{kcal} \mathrm{mol}^{-1}\end{array}$ & $v_{0}-0, \mathrm{~cm}^{-1}$ & $Q_{0}$ \\
\hline $\begin{array}{c}1.2230 \\
0= \\
3.339 \\
\text { M̆ }^{4}\end{array}$ & Quintet & 21.6 & 1552 & $\begin{array}{c}0.040 \\
-0.044\end{array}$ \\
\hline $\begin{array}{c}1.315 \\
O=-0 \\
2.165 \backslash / 2.274 \\
\text { Mo }\end{array}$ & Triplet & 22.4 & 1186 & $\begin{array}{l}-0.186 \\
-0.214\end{array}$ \\
\hline $\begin{array}{ccc}1.3200 \\
0.206 \\
\text { Mo }\end{array}$ & Triplet & 22.2 & 1155 & $\begin{array}{l}-0.127 \\
-0.335\end{array}$ \\
\hline 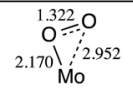 & OSS & 13.1 & 1130 & $\begin{array}{l}-0.342, \\
-0.016\end{array}$ \\
\hline$\underset{1.986 \mathrm{Mo}^{\mathrm{O}} \stackrel{1.440}{\mathrm{O}} \mathrm{O}}{\mathrm{O}}$ & Singlet & 7.3 & 929 & $\begin{array}{l}-0.349 \\
-0.454\end{array}$ \\
\hline
\end{tabular}

Chart 2 The most stable $\mathrm{O}_{2}$ adducts to the $(1,2)$ isomer of $\boldsymbol{1}_{\text {redze }}$ with different spin states and their Gibbs free energy, $\mathrm{O}-\mathrm{O}$ bond stretching vibrational frequency and Atomic Polar Tensor (APT) charges on oxygen atoms $\left(Q_{O}\right)$. The $\Delta G_{298}$ values are relative to the plenary, non-defect structure.

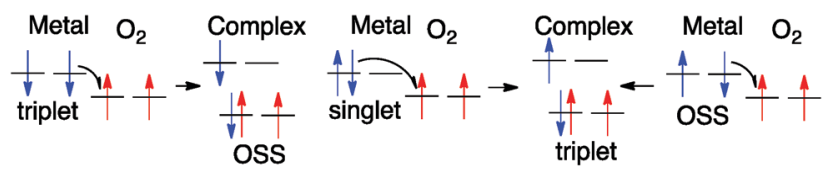

Scheme 3 Schematic representation of oxygen interactions with metals of various electronic states.

structures of the 2e-reduced polyoxometalates have singlet electronic configurations in the ground state, but the triplet states are only a few $\mathrm{kcal} \mathrm{mol}^{-1}$ higher in energy, and thus, the oxygen complexes may have different multiplicities, Scheme 3. Interaction between the defect structures in the singlet state with an oxygen molecule results in the formation of a superoxo $\eta^{2}-\mathrm{O}_{2}$ adduct in the triplet state. Oxygen interaction with the defect structures in the triplet state might lead to superoxo complexes in the open shell singlet (OSS) electronic configuration. In both cases, consequent intramolecular ET yields closed-shell $\eta^{2}-\mathrm{O}_{2}$ peroxo complexes.

Depending on the spin state, oxygen coordination to $\mathbf{1}_{\text {red2e }}$ features various kinds of interaction, from weak bonding (quintet) to superoxo (triplet) and peroxo (singlet), Chart 2 and Fig. S12 (ESI+). ${ }^{32}$ For some superoxo complexes, we succeeded in locating spin symmetry-broken solutions. Calculations show that the OSS states are lower in energy and correspond to somewhat stronger $\mathrm{O}_{2}$ activation than the triplet state.

The calculated reaction profiles for the oxidation reaction of $\mathbf{1}_{\text {red2e }}$ are shown in Fig. 3. In contrast to $\mathbf{1}_{\text {red1e }}$, water coordination does not promote defect formation in these complexes, or only barely does so. Very similar to the case for the re-oxidation of $\mathbf{1}_{\text {redie }}$, the two-competitive rate-limiting states in these systems are defect formation and barrier-less (spin allowed, Scheme 3) $\mathrm{O}_{2}$ coordination with formation of the triplet superoxo $\eta^{2}-\mathrm{O}_{2}$ adduct. The next stage of the interaction, intramolecular ET resulting in a much more stable singlet peroxo $\eta^{2}-\mathrm{O}_{2}$ complex, could potentially have a finite barrier. However, for such transition metal systems,

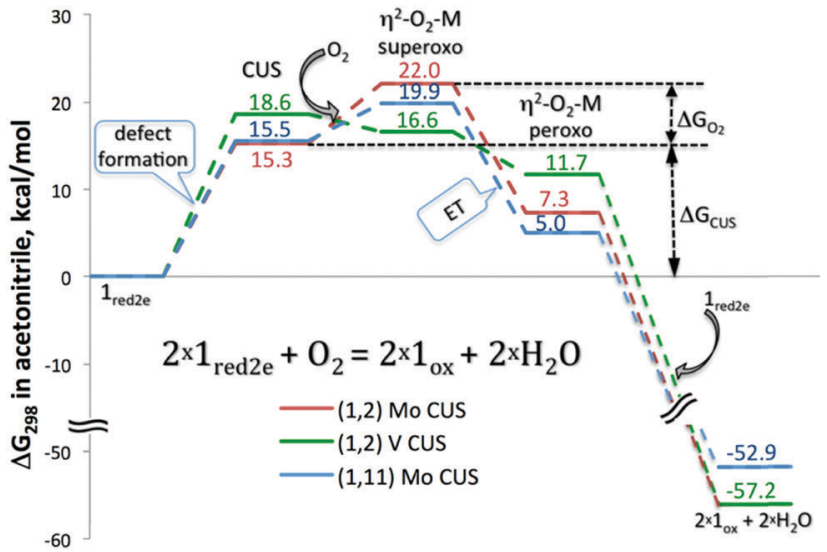

Fig. 3 Reaction profiles for the oxidation of $\mathrm{H}_{7} \mathrm{PV}_{2} \mathrm{MO}_{10} \mathrm{O}_{40}, \mathbf{1}_{\text {redze. }}$

spin crossing probabilities were shown to be close enough to unity, so that they will not materially affect reaction rates. ${ }^{33}$ The subsequent stages of the reaction are very similar to those for the re-oxidation of $\mathbf{1}_{\text {red1e }}$ and involve intermolecular $\mathrm{H}$-transfers from another $\mathbf{1}_{\text {red2e }}$ species, resulting in dissociation of two water molecules and recovery of the intact Keggin structure. As in the case of 1e-reduced polyoxometalates, inspection of the reaction profiles in Fig. 3 shows that for Mo CUSs, oxygen coordination represents the highest energy state of the pathway. In contrast, for activation at vanadium, $\mathrm{V}$ CUS defect formation would appear to be the rate determining factor of the reaction while the following $\mathrm{O}_{2}$ coordination proceeds with some energy gain in this case.

Although, using the broken spin-symmetry approximation, we found the OSS $\eta^{2}-\mathrm{O}_{2}$ superoxo complexes to be more stable than their triplet isomers (vide infra), these reaction profiles are energetically less favourable because of the high energy of the previous stage of interaction, i.e. formation of the defect structure in the triplet state.

In order to bridge between the experimental and computational kinetic data, the energetic span model of Kozuch and co-workers can be applied..$^{34-36}$ This model is based on Eyring's transition state theory together with the concept of rate-determining states rather than rate-determining steps. In such a way, one can retrieve the computed activation energies for oxidation of different forms of $\mathbf{1}_{\text {red }}$ on three coordinatively unsaturated sites, Table 4 .

The following conclusions could be drawn from the comparison of experimental and computational data presented in this work.

Table 4 Calculated apparent activation energies for the aerobic oxidation of different forms of $1_{\text {red }}$

\begin{tabular}{lllll}
\hline 1 & & $\begin{array}{l}\Delta H_{298}^{\#}, \\
\mathrm{kcal} \mathrm{mol}^{-1}\end{array}$ & $\begin{array}{l}\Delta S_{298}^{\#}, \\
\mathrm{cal} \mathrm{mol}^{-1} \mathrm{~K}^{-1}\end{array}$ & $\begin{array}{l}\Delta G_{298}^{\#} \\
\mathrm{kcal} \mathrm{mol}^{-1}\end{array}$ \\
\hline 1 $_{\text {red1e }}$ & Mo (1,2) & 14.6 & -27.2 & 22.7 \\
& $\mathrm{Mo}(1,11)$ & 10.2 & -33.1 & 20.0 \\
& $\mathrm{~V}(1,2)$ & 24.5 & 7.4 & 22.3 \\
1 $_{\text {red2e }}$ & Mo (1,2) & 13.8 & -27.6 & 22.0 \\
& Mo(1,11) & 11.5 & -28.2 & 19.9 \\
& $\mathrm{~V}(1,2)$ & 19.3 & 2.2 & 18.6
\end{tabular}


(i) The experimental results showed that the oxidations with $\mathrm{O}_{2}$ of both the one- and two-electron reduced polyoxometalates are first-order in $\mathbf{1}_{\text {red }}$ and $\mathrm{O}_{2}$ with entropy-driven kinetics. The intermediate species shown in Chart 2 found by computation supported an inner sphere mechanism of these oxidation reactions with oxygen coordination as a rate determining state. Together, inspection of the reaction profiles for oxidation of $\mathbf{1}_{\text {red }}$ and kinetic parameters collected in Table 4 show that the stationary points defining the overall apparent activation barrier for Mo CUSs are always the energies of the superoxo complexes. In accordance with the experimental results, these reactions are entropy-driven. The rate-limiting state for oxygen activation on $\mathrm{V}$ is clearly enthalpy-driven CUS formation. This reaction pathway is higher in energy than that on the Mo CUS for $\mathbf{1}_{\text {red1e }}$ and thus is not expected to be experimentally observed for 1e-reduced polyoxometalates. For $\mathbf{1}_{\text {red2e }}$, both reaction pathways are energetically comparable; however, Mo CUSs are more common than V CUSs in $\mathrm{H}_{5} \mathrm{PV}_{2} \mathrm{Mo}_{10} \mathrm{O}_{40}$ (only two out of five isomers have $\mathrm{V}$ atoms in adjoining positions, and even in these cases there are $7 \mathrm{~V}-\mathrm{O}-\mathrm{Mo}$ bonds per each $\mathrm{V}-\mathrm{O}-\mathrm{V}$ bond). Thus, we expect that depending on the relative number of isomers and on the reaction temperature, the kinetics of the Mo CUS or V CUS driven reaction profiles could be observed in the experiments.

(ii) It is notable that theoretically $\mathrm{O}_{2}$ activation by $\mathbf{1}_{\text {red1e }}$ is slightly preferred for the $(1,11)$ isomer compared to the $(1,2)$ isomer. In fact, in an EPR experiment where one can differentiate between $\mathbf{1}_{\text {red1e }}$ species with vicinal and distal vanadium atoms, ${ }^{10,11}$ we found that the species associated with distal isomers, e.g. the $(1,11)$ isomer, were oxidized faster than the species associated with vicinal vanadium atoms.

(iii) Since the reduction of $\mathrm{O}_{2}$ to $\mathrm{H}_{2} \mathrm{O}$ is a four-electron process, additional intermolecular electron transfer and proton transfer steps are needed to split the $\mathrm{O}-\mathrm{O}$ bond and form water after initial interaction of $\mathrm{O}_{2}$ with the reduced polyoxometalate. The fact that the reaction is first-order in the polyoxometalate and $\mathrm{O}_{2}$, together with the calculated energies of the intermediate hydrogen transfer reactions, clearly indicates that these latter reactions are fast relative to the $\mathrm{O}_{2}$ activation step.

(iv) For $\mathbf{1}_{\text {red2e }}$, the experimental and computed kinetic parameters $\left(\Delta G^{\#}, \Delta H^{\#}\right.$ and $\left.\Delta S^{\#}\right)$ are similar and also very similar to

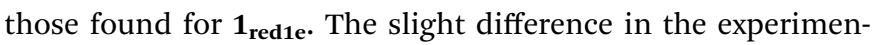
tally found $\Delta G^{\#}$ explains the faster rate constant found for $\mathbf{1}_{\text {red2e }}$, but this is not so obvious from the calculated data.

\section{Experimental}

\section{Preparation of the reduced polyoxometalate}

The oxidized plenary Keggin compound, $\mathrm{H}_{5} \mathrm{PV}_{2} \mathrm{Mo}_{10} \mathrm{O}_{40}, \mathbf{1}_{\mathbf{o x}}$, was prepared using the published method. ${ }^{37}$ One- or twoelectron reduced forms were prepared in organic solvents by reduction with $\mathrm{H}_{2}$ using a $10 \% \mathrm{Pt} / \mathrm{C}$ catalyst or with organic substrates. The degree of reduction was spectrophotometrically verified at $750 \mathrm{~nm}$ by titration with $m$-chloroperbenzoic acid and verified also by oxidation using a standardized solution of $\mathrm{Br}_{2}$ as oxidant. The reduced polyoxometalate was stored under argon.
Precise values for the extinction coefficient $\varepsilon$ of the one- or twoelectron reduced polyoxometalates were determined by titration with $m$-chloroperbenzoic acid. Using this method, for $1_{\text {red1e }}$ an extinction coefficient of $\varepsilon_{750}=1.1+0.2 \times 10^{3} \mathrm{M}^{-1}$ $\mathrm{cm}^{-1}$ was found and for $1_{\text {red2e }}, \varepsilon_{750}=2.2+0.3 \times 10^{3} \mathrm{M}^{-1} \mathrm{~cm}^{-1}$.

\section{Kinetics measurements}

Reactions of reduced $\mathbf{1}_{\text {red }}$ with $\mathrm{O}_{2}$ were carried out in various organic solvents. Known amounts of $\mathbf{1}_{\text {red }}$ were treated with a solution saturated with pure $\mathrm{O}_{2}$, air or $\mathrm{O}_{2} / \mathrm{Ar}$ mixtures in spectrophotometric cuvettes. Measurements were carried out on an Agilent 8453 diode array spectrometer equipped with a temperature controller nominally accurate to $0.1{ }^{\circ} \mathrm{C}$. Changes in absorption with time at various concentrations and temperatures were observed at $750 \mathrm{~nm}$. The initial rates were derived from these absorption versus time data when plots were linear (about 10\% conversion). The solubility of $\mathrm{O}_{2}$ in air-equilibrated $\mathrm{CH}_{3} \mathrm{CN}$ is $1.6 \mathrm{mM}$ or $8.1 \mathrm{mM}$ in $\mathrm{O}_{2}$ saturated $\mathrm{CH}_{3} \mathrm{CN}$ at $25{ }^{\circ} \mathrm{C} .{ }^{38,39}$

\section{Cyclic voltammetry}

Measurements were carried out at $25{ }^{\circ} \mathrm{C}$ under an argon atmosphere using an EC-Lab VCP-201 electrochemical workstation (BioLogic Science Instruments). A standard three-electrode electrochemical cell was employed with a glassy carbon disk (surface area $0.071 \mathrm{~cm}^{2}$ ) as the working electrode, a platinum wire as the counter electrode, and $\mathrm{Ag}$ wire as the reference electrode. The scan rate used was $100 \mathrm{mV} \mathrm{s}^{-1}$. Potentials measured versus $\mathrm{Ag} / \mathrm{Ag}^{+}$were converted to the $\mathrm{Fc} / \mathrm{Fc}^{+}(\mathrm{Fc}=$ ferrocene) scale by analysis of cyclic voltammetry of ferrocene in acetonitrile under same conditions $\left(0.1 \mathrm{M} \mathrm{Bu}_{4} \mathrm{NClO}_{4} 50 \mathrm{mM}\right.$ trifluoroacetic acid) in acetonitrile.

\section{Computational methods}

All computations were done using a locally modified version of the Gaussian 09 package. ${ }^{40}$ Geometry optimizations and harmonic frequency evaluations were performed using the nonempirical GGA density functional ${ }^{41,42} \mathrm{PBE}^{43}$ in conjunction with the PC1 basis set. The latter is a combination of Jensen's polarization consistent pc-1 basis set ${ }^{44-46}$ for the main group elements and $\mathrm{V}$ and the Stuttgart-Dresden-Dolg (SDD) basis set-RECP (relativistic energy-consistent pseudopotential) combination ${ }^{47}$ for molybdenum; to the latter, a single f-type polarization function was added, the exponent being the geometric average of the two f-exponents given by Martin and Sundermann. ${ }^{48}$ This combination is of double- $\zeta$ plus polarization quality. In order to speed up the calculations, we applied the density fitting (DF) approximation ${ }^{49-51}$ for calculating the two-electron (Coulomb) integrals. This approximation is known to speed up pure-DFT calculations on large systems by 1-2 orders of magnitude. The auxiliary basis sets required for this were generated by the automatic algorithm as implemented in Gaussian 09. Thus, geometries of all the complexes were optimized at the PBE-DF/PC1 level of theory without symmetry constraints. Subsequently, singlepoint calculations at the optimized geometries were performed using the empirical hybrid meta-GGA functional M06 ${ }^{52}$ combined with the same basis set (M06/PC1), as well as using the PBE functional but combined with a larger AUG-PC1 basis set. 
The AUG-PC1 basis set represents a combination of the aug-pc-1 basis set on the main group elements and vanadium ${ }^{44-46,53,54}$ and the SDD basis set with added $\mathrm{f}$ basis functions on molybdenum. The final level of theory applied in the present work is thus the additivity approximation $E_{\mathrm{e}}[\mathrm{M} 06 / \mathrm{AUG}-\mathrm{PC} 1] \approx E[\mathrm{PBE}-\mathrm{DF} / \mathrm{AUG}-$ $\mathrm{PC} 1]-E[\mathrm{PBE}-\mathrm{DF} / \mathrm{PC} 1]+E[\mathrm{M} 06 / \mathrm{PC} 1]$.

Bulk solvent effects of the acetonitrile medium have been calculated at the M06/PC1 level via the self-consistent reaction field (SCRF) method, ${ }^{55}$ using the continuum solvation model COSMO as implemented in Gaussian 09. ${ }^{56,57}$ Dispersion interactions within the computed structures are partially accounted for in the M06 functional. Adding the D3 empirical dispersion correction term,${ }^{58,59}$ further improved the energies by considering long interactions. No D3(BJ) parameters for M06 are available from the Grimme group; ${ }^{60}$ as we optimized parameters for many additional functionals in the framework of a large benchmark project for noncovalent interactions, ${ }^{61}$ we found the D3(BJ) optimization for M06 to be divergent.

Oxygen is a triplet in its ground state while oxidized products usually have a closed-shell electronic configuration. Therefore, reactions of molecular oxygen often involve a step of intersystem crossing. Thus, we considered doublet and quartet states for 1e-reduced complexes and closed- and open-shell singlet, triplet and quintet states for 2e-reduced complexes. Spin contamination was negligible for all wave functions except for open-shell singlets, for which the broken-symmetry wave functions were contaminated by triplet state with $\left\langle S^{2}\right\rangle$ close to 1 . In this case the energy was corrected using the sum method of Cramer and Ziegler ${ }^{62}$ according to the equation

$$
E_{\mathrm{OSS}}=\frac{2 E_{\mathrm{S}+\mathrm{T}}-E_{\mathrm{T}}\left\langle S^{2}\right\rangle}{2-\left\langle S^{2}\right\rangle}
$$

where $E_{\mathrm{S}+\mathrm{T}}$ is the energy of the broken symmetry unrestricted DFT wave function for the optimized geometry; $E_{\mathrm{T}}$ is the energy of the triplet state with the same geometry; and $\left\langle S^{2}\right\rangle$ is the value obtained in the calculations.

The calculations were performed for two isomers, $(1,2)$ with adjacent vanadium atoms and $(1,11)$ with the most distant vanadium atoms. If not stated otherwise, the energetic results present Gibbs free energy in acetonitrile at $298 \mathrm{~K}$ and relate to the $(1,2)$ isomer. Presented enthalpy values involve the same corrections as $\Delta G$, i.e. correction for AUG-PC1, Grimme's dispersion correction D3 for M06 functional and solvation correction.

\section{Conclusions}

This combined experiment and computational study provides, for the first time, important insights into the oxidation by $\mathrm{O}_{2}$ of one- and two-electron reduced $\mathrm{H}_{5} \mathrm{PV}_{2} \mathrm{Mo}_{10} \mathrm{O}_{40}$ species, which is one of the key steps in many aerobic catalytic cycles. ${ }^{7-9}$ The experimental kinetic studies show that the reactions are first-order in both the polyoxometalate and $\mathrm{O}_{2}$, where the rate constants are somewhat higher for the two-electron reduced species. Solvents have a considerable effect, protic solvents being preferred over aprotic solvents-presumably the protons are aiding in the formation of coordinatively unsaturated sites (CUSs). Reduction of $\mathrm{H}_{5} \mathrm{PV}_{2} \mathrm{Mo}_{10} \mathrm{O}_{40}$ by an ET $\left(\mathrm{H}_{2}\right)$ or ET-OT $\left(\mathrm{Ph}_{3} \mathrm{P}\right)$ reaction showed similar reoxidation kinetics (rate constants and activation parameters). The entropy of activation is strongly negative, indicating a significant reorganization energy in the transition state because two species interact to form one species. DFT calculations and experiments carried out on the re-oxidation reactions suggest an inner-sphere process for $\mathrm{O}_{2}$ activation in contrast with what was observed with the isostructural tungstates. ${ }^{15-17}$ The reaction pathways proceed by the formation of a CUS, and then the binding of $\mathrm{O}_{2}$, to form a superoxo $\eta^{2}-\mathrm{O}_{2}$ adduct. After formation of this superoxo $\eta^{2}-\mathrm{O}_{2}$ adduct, additional inter- and intramolecular ET and CPET steps lead to O-O bond cleavage and formation of $\mathrm{H}_{2} \mathrm{O}$. Most interestingly, although vanadium is the reactive redox centre for oxidation of substrates (reducing agents) and a necessary component for the oxidative activity of $\mathrm{H}_{5} \mathrm{PV}_{2} \mathrm{Mo}_{10} \mathrm{O}_{40}$ - and a CUS can be formed at both Mo and $\mathrm{V}$ sites $-\mathrm{O}_{2}$ coordination occurs at the Mo CUSs, preferably those where the vanadium centres are distal to each other. This may be at least a partial explanation of the unique activity of $\mathrm{H}_{5} \mathrm{PV}_{2} \mathrm{Mo}_{10} \mathrm{O}_{40}$, as opposed to monomeric or oligomeric vanadates, such as decavanadate where $\mathrm{V}(\mathrm{Iv})$ species are inert to oxidation with $\mathrm{O}_{2}$.

\section{Conflicts of interest}

There are no conflicts to declare.

\section{Acknowledgements}

This research was supported by the Israel Science Foundation Grants 763/14 and 1358/15, the Israel Ministry of Science and Technology, and the Lise Meitner Centre for Computational Quantum Chemistry. The authors would like to thank Mr Nitai Sylvetsky for assistance with editing the manuscript.

\section{Notes and references}

1 S. S. Stahl, Angew. Chem., Int. Ed., 2004, 43, 3400-3420.

2 I. V. Kozhevnikov, Catalysis by Polyoxometalates, Wiley, Chichester, England, 2002.

3 C. L. Hill and C. M. Prosser-McCartha, Coord. Chem. Rev., 1995, 143, 407-455.

4 T. Okuhara, N. Mizuno and M. Misono, Adv. Catal., 1996, 41, 113-252.

5 I. A. Weinstock, R. E. Schreiber and R. Neumann, Chem. Rev., 2018, DOI: 10.1021/acs.chemrev.7b00444.

6 S.-S. Wang and G.-Y. Yang, Chem. Rev., 2015, 115, 4893-4962.

7 R. Neumann and A. M. Khenkin, Chem. Commun., 2006, 2529-2538.

8 R. Neumann, Inorg. Chem., 2010, 49, 3594-3601.

9 R. Neumann, Adv. Inorg. Chem., 2017, 69, 67-90.

10 H. Goldberg, I. Kaminker, D. Goldfarb and R. Neumann, Inorg. Chem., 2009, 48, 7947-7952. 
11 I. Kaminker, H. Goldberg, R. Neumann and D. Goldfarb, Chem. - Eur. J., 2010, 16, 10014-10020.

12 I. Efremenko and R. Neumann, J. Am. Chem. Soc., 2012, 134, 20669-20680.

13 B. B. Sarma, R. Carmieli, A. Collauto, I. Efremenko, J. M. L. Martin and R. Neumann, ACS Catal., 2016, 6, 6403-6407.

14 D. Barats, G. Leitus, R. Popovitz-Biro, L. J. W. Shimon and R. Neumann, Angew. Chem., Int. Ed., 2008, 47, 9908-9912.

15 Y. V. Geletii, C. L. Hill, R. H. Atalla and I. A. Weinstock, J. Am. Chem. Soc., 2006, 128, 17033-17042.

16 O. Snir, Y. Wang, M. E. Tuckerman, Y. V. Geletii and I. A. Weinstock, J. Am. Chem. Soc., 2010, 132, 11678-11691.

17 O. Snir, Y. Wang and I. A. Weinstock, Isr. J. Chem., 2011, 51, 247-259.

18 M. Sadakane and E. Steckhan, Chem. Rev., 1998, 98, 219-237.

19 R. Neumann and M. Levin, J. Am. Chem. Soc., 1992, 114, 7278-7286.

20 C. D. Duncan and C. L. Hill, J. Am. Chem. Soc., 1997, 119, 243-244.

21 J. H. Grate, J. Mol. Catal., 1996, 114, 93-101.

22 E. G. Zhizhina, V. F. Odyakov, M. V. Simonova and K. I. Matveev, Kinet. Catal., 2005, 46, 354-363.

23 S. Sahu and D. P. Goldberg, J. Am. Chem. Soc., 2016, 138, 11410-11428.

24 S. Hong, Y. Lee, K. Ray and W. Nam, Coord. Chem. Rev., 2017, 334, 25-42.

25 P. M. Wood, Biochem. J., 1988, 253, 287-289.

26 S. Hammes-Schiffer, Acc. Chem. Res., 2001, 34, 273-281.

27 S. P. Neville, O. M. Kirkby, N. Kaltsoyannis, G. A. Worth and H. H. Fielding, Nat. Commun., 2016, 7, 11357.

28 G. G. Hammes, Thermodynamics and Kinetics for the Biological Sciences, John Wiley \& Sons, Inc., USA and Canada, 2000.

29 C. Song and J. Zhang, PEM Fuel Cell Electrocatalysts and Catalyst Layers, Springer-Verlag, London, 2008, p. 88.

30 M. Setvin, U. Aschauer, J. Hulva, T. Simschitz, B. Daniel, M. Schmid, A. Selloni and U. Diebold, J. Am. Chem. Soc., 2016, 138, 9565-9571.

31 A. F. Cozzolino, D. Tofan, C. C. Cummins, M. Temprado, T. D. Palluccio, E. V. Rybak-Akimova, S. Majumdar, X. Cai, B. Captain and C. D. Hoff, J. Am. Chem. Soc., 2012, 134, 18249-18252.

32 P. L. Holland, Dalton Trans., 2010, 39, 5415-5425.

33 R. Poli and J. M. Harvey, Chem. Soc. Rev., 2003, 32, 1-8.

34 S. Kozuch and S. Shaik, J. Am. Chem. Soc., 2006, 128, 3355-3365.

35 S. Kozuch and J. M. L. Martin, ChemPhysChem, 2011, 12, 1413-1418.

36 S. Kozuch and S. Shaik, Acc. Chem. Res., 2011, 44, 101-110.
37 G. A. Tsigdinos and C. J. Hallada, Inorg. Chem., 1968, 7, 437-441.

38 D. T. Sawyer, A. Sobkowiak and L. L. Roberts Jr., Electrochemistry for Chemists, Wiley, New York, 2nd edn, 1995, p. 505.

39 Q. Li, C. Batchelor-McAuley, N. C. Lawrence, R. S. Hartshorne and R. G. Compton, J. Electroanal. Chem., 2013, 688, 328-335.

40 M. J. Frisch, G. W. Trucks, H. B. Schlegel, G. E. Scuseria, M. A. Robb, J. R. Cheeseman, G. Scalmani, V. Barone, B. Mennucci and G. A. Petersson, et al., Gaussian 09, Rev. E01, Gaussian, Inc., Wallingford, CT, 2012, http://www. gaussian.com.

41 W. Kohn and L. J. Sham, Phys. Rev. [Sect.] A, 1965, 140, 1133-1138.

42 R. G. Parr and W. Yang, Density Functional Theory of Atoms and Molecules, Oxford University Press, New York, 1970, p. 230.

43 J. P. Perdew, K. Burke and M. Ernzerhof, Phys. Rev. Lett., 1996, 77, 3865-3868. Erratum, Phys. Rev. Lett., 1997, 78, 1396.

44 F. Jensen, J. Chem. Phys., 2001, 115, 9113-9125.

45 F. Jensen, J. Chem. Phys., 2002, 116, 7372-7379.

46 F. Jensen, J. Chem. Phys., 2013, 138, 014107.

47 M. Dolg, in Modern Methods and Algorithms of Quantum Chemistry, ed. J. Grotendorst, Jülich, 2000, vol. 1, pp. 479-508.

48 J. M. L. Martin and A. Sundermann, J. Chem. Phys., 2001, 114, 3408-3420.

49 B. I. Dunlap, J. Chem. Phys., 1983, 78, 3140-3142.

50 B. I. Dunlap, THEOCHEM, 2000, 529, 37-40.

51 A. B. Nadykto, H. Dua and F. Yu, Vib. Spectrosc., 2007, 44, 286-296.

52 Y. Zhao and D. G. Truhlar, J. Chem. Phys., 2006, 125, 194101.

53 F. Jensen, J. Chem. Phys., 2002, 117, 9234-9240.

54 F. Jensen, J. Chem. Phys., 2003, 118, 2459-2463.

55 M. Cossi, G. Scalmani, N. Rega and V. Barone, J. Chem. Phys., 2002, 117, 43-54.

56 A. Klamt and G. Schüürmann, J. Chem. Soc., Perkin Trans. 2, 1993, 799-805.

57 V. Barone and M. Cossi, J. Phys. Chem. A, 1998, 112, 1995-2001.

58 S. Grimme, J. Antony, S. Ehrlich and H. A. Krieg, J. Chem. Phys., 2010, 132, 154104.

59 S. Grimme, S. Ehrlich and L. Goerigk, J. Comput. Chem., 2011, 32, 1456-1465.

60 S. Grimme, DFTD3 website, via http://www.thch.uni-bonn.de.

61 B. Brauer, M. K. Kesharwani, S. Kozuch and J. M. L. Martin, Phys. Chem. Chem. Phys., 2016, 18, 20905-20925.

62 W. T. G. Johnson, M. B. Sullivan and C. J. Cramer, Int. J. Quantum Chem., 2001, 85, 492-508. 